\title{
Les cellules capables de phagocytose chez les Insectes
}

\author{
par J. CARAYON \\ Laboratoire d'Entomologie, Muséum national d'Histoire naturelle, \\ 45, rue Buffon, 75005 Paris
}

Dans son ouvrage sur les réactions cellulaires de défense chez les insectes, Salt (1970) écrit, p. 11 : «Phagocytosis in insects is carried out exclusively by blood cells. 》 Comme il le précise un peu plus loin, les cellules sanguines intervenant dans la phagocytose sont surtout les «plasmatocytes». Ce terme, proposé par Yeager (1945) et généralement adopté depuis la mise au point de Jones (1962), est, soit dit en passant, fort mauvais. Il a le grave inconvénient d'être presque semblable au mot «plasmocytes » qui désigne chez les vertébrés des cellules sanguines très différentes par leur structure et par leur fonction des plasmatocytes d'insectes, auxquels il est bien préférable de laisser le nom antérieur d' \& amoebocytes ».

La phagocytose est l'incorporation puis la destruction dans une cellule d'éléments figurés inertes ou vivants que leurs dimensions permettent de voir au microscope photonique. Cette définition, la seule possible d'après les données aujourd'hui disponibles, reste valable quelle que soit la manière, sans doute assez variée, mais connue en de rares cas seulement, dont se réalise le phénomène. Elle implique notamment que les éléments phagocytés soient « captés » par les phagocytes ou qu’ils y pénètrent activement.

Les cellules d'insectes capables de phagocytose ainsi définie sont bien plus diverses que ne le pense Salt. Sans reparler des hémocytes, voici les catégories où elles se rangent avec, à leur sujet, quelques indications très succinctes, les unes tirées de la littérature, les autres, plus nombreuses, résultant de mes recherches sur les inséminations extragénitales traumatiques. Ces inséminations, je le rappelle, se rencontrent chez certains Hémiptères Cimicoidea où le mâle, lors de l'accouplement, injecte toujours le sperme en abondance dans l'hémocœle de la femelle; les spermatozoïdes, qui doivent ensuite émigrer à travers le sang et divers tissus pour atteindre les ovocytes, sont en majeure partie détruits au cours de leur trajet par phagocytose.

- Adipocytes. Salt (1970) juge erronée la seule observation qu'il mentionne de phagocytose par des adipocytes (Cameron, 1934), car, selon lui, les cellules opérant 
cette phagocytose sont en réalité des hémocytes infiltrés dans le tissu adipeux. Il ignore les travaux signalant l'action macrophagique des adipocytes lors de la métamorphose (Poyarkor̃, 1910 ; Hufnagel, 1918 ; Murray et Tiegss, 1935) et chez certains Hémiptères à insémination traumatique (Carayon, $1952 a$ et $b$ ). Dans ce dernier cas, du moins, il est indubitable que les adipocytes peuvent, après une dédifférenciation plus ou moins importante, qui a été suivie en détail, phagocyter nombre de spermatozoïdes.

- Mycétocytes. Dérivés le plus souvent des adipocytes, les mycétocytes, isolés ou groupés en mycétomes, hébergent des microorganismes symbiotiques. Ils les détruisent généralement de telle manière qu'ils en compensent la multiplication. D'après mes observations inédites chez des Hémiptères où la symbiose disparaît au stade imaginal, cette destruction devient alors totale et semblable à une phagocytose typique.

- Cellules péricardiales. Dans la plupart des cas, elles ne résorbent que des particules colloïdales de diamètre infra-microscopique. Toutefois, chez divers Hémiptères à insémination traumatique, certaines d'entre elles, qui apparaissent groupées et plus ou moins modifiées (collophages), phagocytent aussi une partie des spermatozoïdes, soit uniquement lorsque ces derniers sont surabondants, soit chez quelques espèces, de manière habituelle (Carayon, 1975).

- Cellules folliculaires. On sait qu'elles détruisent par un processus non distinguable de la phagocytose l'ovocyte qu'elles entourent, si celui-ci commence à s'altérer. Il est moins connu que des cellules folliculaires, groupées à la base des ovarioles et variablement différenciées (corps spermatolysants), phagocytent la plupart des spermatozoïdes qui y pénètrent chez nombre d'Hémiptères à insémination traumatique (Carayon, 1966, 1975).

- Cellules épithéliales. Toujours chez les Hémiptères à insémination traumatique, la région du tégument abdominal femelle que le mâle perfore lors de l'accouplement est souvent préalablement modifiée (ectospermalège). Les cellules épithéliales y sont bien plus volumineuses et différentes de celles du tégument normal. D'après des observations personnelles inédites, elles peuvent phagocyter des spermatozoïdes, mais uniquement dans des conditions sub-pathologiques (forte surabondance de spermatozoïdes ou inséminations traumatiques hétérospécifiques).

\section{Bibliographie}

Cameron (G. R.), 1934. - Inflammation in the caterpillars of Lepidoptera. J. Path. Bact., $38,441-466$.

Carayon (J.), $1952 a$. - Les fécondations hémocœliennes chez les Hémiptères Nabidae du genre Alloeorhynchus. C.R. Acad. Sci., 234, 571-573.

Carayon (J.), $1952 b$. - Les fécondations hémoccliennes chez les Hémiptères Nabidae du genre Prostemma. C.R. Acad. Sci., 234, 1220-1222. 
CARAYON (J.), 1966. - Traumatic inseminetion and the paragenital system, in Usinger: Monograph of Cimicidie, pp. 81-166. Ed. Entom. Soc. Amer., Baltimore, U.S.A.

CARAYON (J.), 1975. - Insémination extragénitale traumatique et système paragénital chez les Hémiptères Cimicoidea. Thèse Doctorat ès-Sciences, Univ. Paris VI, $\mathrm{n}^{\circ}$ ordre A.O. $10.889,1$ vol., 237 p.

Carayon (J.), 1976. - Insémination extragénitale traumatique, in Traité de Zoologie, sous la direction de P.-P. Grassé. T. VIII, fasc. 5, pp. 351-390, Masson, édit., Paris.

HufNagel (A.), 1918. - Recherches histologiques sur la métamorphose d'un Lépidoptère (Hyponomeuta padella L.). Arch. Zool., 57, 47-202.

JoNes (J. C.), 1962. - Current concepts concerning insect hemocytes. Am. Zool., 2, 209-246.

Murray (F. V.) et Tiegs (O. W.), 1935. - The metamorphosis of Calandra oryzae. Quart. J. micr. Sci., 77, 405-495.

Poyarkoff (E.), 1910. - Metamorphose chez Galerucella. Arch. Anat. micr., 12, 333-371.

SAlt (G.), 1970. - The cellular defence reactions of Insects. Cambridge, Mon. exp. Biol., T. 16, Cambridge University Press, édit., New York, 117 p.

YEAGER (J.F.), 1945. - The blood picture of the southern armyworm (Prodenia eridiana). J. Agr. Res., 71, 1-40. 